\title{
O ENSINO DO LÉXICO: DO PROBLEMA DO DICIONÁRIO À VIVÊNCIA DA LINGUAGEM ${ }^{1}$
}

\author{
Marcos Luiz Cumpri * \\ Raquel da Silveira **
}

\begin{abstract}
Resumo: Este artigo versa sobre o ensino de semântica lexical em língua materna na Educação Básica. Na primeira parte, falamos do problema do sentido lexical e defendemos que as relações de sentido possíveis das unidades da língua dependem da articulação de vários domínios, entre eles o gramatical, o contextual e o psicológico. Na segunda, alertamos para a necessidade de uso de dicionários apropriados nas escolas com especial atenção para o nível de ensino em que o aluno se encontra e para os fins específicos da aprendizagem. $\mathrm{Na}$ terceira e última parte, retomamos as seções anteriores ao expormos as razões que justificam as falhas e os possíveis sucessos no uso do dicionário em sala aula.
\end{abstract}

Palavras-chave: Léxico. Ensino. Sentido. Dicionário.

\begin{abstract}
This paper focuses on the teaching of lexical semantics in the mother tongue in Basic Education. In the first part, issues on lexical sense are presented. The points argued deal with possible relations of meaning that depend on the articulation of several areas, including grammar, context and Psychology. In the second part, attention is called to the need for appropriate dictionaries to be used in schools with special attention to the grade and to the specific purposes of learning. Finally, in the last part, the previous sections are revisited by exposing the reasons that explain the fails and possible successes in the use of the dictionary in the classroom.
\end{abstract}

Keywords: Lexicon. Teaching. Meaning. Dictionary.

\section{Introdução}

Quando a criança adentra o universo escolar ${ }^{2}$, traz consigo um conhecimento linguístico que é fruto de um percurso feito rumo à elaboração de sua linguagem e isso lhe garante o aprendizado de outras modalidades da língua dentro e fora da escola. Porém, à escola fica designada a incumbência de ensinar, sobretudo, a modalidade escrita. (SCARPA, 2009).

Esse raciocínio demonstra que não é sem rigor que as atividades com a língua materna estão prioritariamente direcionadas aos processos de alfabetização. Contudo, a falta de recursos léxico-gramaticais mais sofisticados e de outros segmentos formativos (sobretudo os culturais) impulsiona a criança a transmitir e a compreender conhecimento por um prisma mais sensorial e afetivo. Por outro lado, durante as atividades escolares, a criança passa a somar ao seu ainda limitado conhecimento de mundo as aquisições que fazem parte do processo de educação, o que naturalmente a conduz a ampliar o conhecimento de língua e a ter acesso a tramas de sentidos até então inéditas.

A celeuma não para por aí. Além das dificuldades naturais com que a criança se depara, por ter um vocabulário naturalmente escasso, há aquelas relacionadas à interpretação dos possíveis sentidos a serem atribuídos a uma mesma palavra a depender do contexto, o que

\footnotetext{
${ }^{1}$ Apoio: Capes

* Doutor em Linguística e Língua Portuguesa - Universidade do Estado de Mato Grosso. Endereço eletrônico: marcoscumpri@yahoo.com.br

** Discente do Curso de Letras da Universidade de Santa Cruz do Sul. Endereço eletrônico: raquelsilveira73@hotmail.com

${ }^{2}$ Aqui nos referimos ao início da educação básica.
} 
se agrava quando a solução se aponta para um recurso muito comum, pouco produtivo: o uso do dicionário ${ }^{3}$.

Diante do exposto acima, propomos, para este artigo, refletir sobre o ensino da semântica do léxico em língua materna destacando algumas experiências que vimos colhendo ao longo de nossa trajetória de pesquisa e de ensino. Como segunda meta, trazemos considerações sobre o uso do dicionário escolar na sala de aula do ensino básico com vistas a defendermos que, apesar de frágeis, quando explicam as relações semânticas no nível discursivo (os provérbios, por exemplo), os dicionários podem fornecer subsídios valiosos ao ensino da língua quando seu uso estiver atrelado à vivência da linguagem.

\section{0 problema motriz: o sentido lexical}

Pensar o sentido lexical como aquele oriundo de diferentes contextos, variando de acordo com o tempo, local e situação em que a palavra tenha sido inserida é uma realidade da qual o ensino de semântica lexical não pode fugir. $\mathrm{Na}$ sala de aula, é preciso tomar a relação entre forma e sentido numa perspectiva dinâmica (o discurso, o texto, a fala), pois é na articulação entre o nível lexical (o morfológico, o paradigmático) e o gramatical (o sintático, o sintagmático) que as nuances de sentido vão se dando. É necessário, então, nas atividades de linguagem na escola, orientar o aluno a analisar mais detalhadamente o contexto e a fazer uma reflexão mais profunda dos fatos abordados nos textos estudados por meio de perguntas que possibilitem ampliar seus conhecimentos, pois "o nosso grau de familiaridade com uma palavra dependerá da frequência e intimidade de nossa vivência com ela". (KLEIMAN, 1998, p. 71).

Em verdade, o que estamos defendendo é que as relações de sentido possíveis das unidades da língua dependem da articulação de vários domínios, entre eles o gramatical, o contextual, o psicológico. Afinal,

A atividade de produção e de reconhecimento de enunciados se faz sempre entre os sujeitos colocados nas situações às vezes empíricas e ao mesmo tempo ligadas às representações imaginárias do estatuto de alguns sujeitos para remeter ao outro, para remeter a uma sociedade, para remeter ao texto, para remeter àquilo que se poderia chamar de "um discurso intertextual", esta espécie de discurso ambiente com os valores que estão ligados às palavras. (CULIOLI, 2002, p. 92, tradução nossa) ${ }^{4}$

Cumpri (2011) relaciona a questão aqui abordada ao ensino do texto e acredita que estabelecer relações de sentidos é explorar as experiências prévias dos alunos e fazer associações de tais experiências com as atividades textuais. Desse modo, o texto seria o resultado de um trabalho sensível e abstrato que passaria pela transformação de noções de cunho psicológico, sociológico, cultural e científico em representações linguísticas.

$\mathrm{O}$ nosso conhecimento de falante nativo com experiência na área nos habilita a reconhecer palavras até então, aparentemente, inéditas. Demonstração disso é que ao ler um

\footnotetext{
3 Aqui, entendemos o dicionário por dois vieses complementares. Ele é, ao mesmo tempo, o depositário do acervo lexical da língua e da cultura e o descritor do léxico em função de um modelo ideal de língua (a língua culta). Maiores esclarecimentos dessa concepção podem ser encontrados em Biderman (1978).

${ }^{4} L$ ' activité de production e de reconnaissance d'énoncés se fait toujours entre des sujets pris dans des situations à la fois empiriques et en même temps liées à des représentations imaginaires du status de chacun des sujets par rapport à l' autre, par rapport à une société, par rapport à du texte, par rapport à ce qu'on purrait appeler «un discours inter-textuel»,cette espèce de discours ambiant des valeurs qui sont liées à des mots.
} 
livro ou uma revista, em geral, não percebemos que algumas daquelas palavras não faziam parte do nosso vocabulário antes da leitura. Como exemplo, podemos citar as palavras sinuosamente, variavelmente, adoravelmente e calmamente; que são advérbios formados pela adição do sufixo - mente a um adjetivo. Se encontrarmos em um texto alguma dessas palavras, não teremos dificuldades para interpretá-las. Essa é uma propriedade de nossas estratégias cognitivas que se apoiam no conhecimento das regras gramaticais e no conhecimento do vocabulário.

Estamos sempre adquirindo (conhecendo) palavras novas pelo uso diário da língua, seja em situações coloquiais (sobretudo as de fala), seja em atividades linguísticas formais em que se predomina a escrita. Esse fato faz com que sempre haja um componente natural nos atos de compreensão e de interpretação, mesmo porque, quando recebemos uma palavra nova ela quase sempre está acompanhada de outras que já conhecemos. São essas outras palavras, junto com a relação espaço-tempo, que formam a base do contexto.

Kleiman (1998) se posiciona de modo a também defender a interpretação espontânea. Seguem suas palavras:

\begin{abstract}
Muitas vezes, continuar lendo após o aparecimento da palavra desconhecida irá deixar claro o significado dessa palavra, pois a definição vem em seguida. Uma vez que o aluno tem a tendência a parar de ler quando encontra uma palavra desconhecida (isto justamente devido às orientações do professor de "sublinhar todas as palavras que desconhece durante a leitura"), ensinar ao aluno a analisar o contexto na procura de pistas implica ensinar, ao mesmo tempo, a fazer uma leitura não linear; isto é, continuar a leitura ainda quando houver incompreensão momentânea, inclusive voltando para trás, relendo, pois o contexto pode elucidar o problema. (KLEIMAN, 1998, p. 75).
\end{abstract}

A melhor maneira para fazer a criança compreender o que é o contexto é fazê-la ler um texto qualquer e dele extrair as possibilidades de significação das unidades da língua. A capacidade para perceber a função do contexto é fulcral na formação escolar da criança porque junto veem outros aprendizados, entre eles a consciência natural da língua enquanto uma representação articulada. Assim, é necessário promover condições para que o aluno desenvolva as habilidades de associação e internalização dos significados diante do contexto e que dele extraia conceitos mais abstratos como o de coesão e coerência textual; geralmente difíceis de serem compreendidos quando optamos por uma abordagem mais formalizada para ensiná-los.

Uma alternativa eficiente para isso é lançarmos mão de trabalhos que envolvam o conhecimento prévio do aluno sobre a estrutura da língua. Como um bom exemplo metodológico há as histórias em quadrinhos que podem apresentar, de uma forma lúdica, o uso metafórico da língua, estabelecendo mais facilmente a relação entre situação e significado, entre léxico e gramática, etc.

$\mathrm{O}$ supradito traz à baila um novo fazer pedagógico que vem ganhando força desde o surgimento dos estudos linguísticos atrelados ao significado. Borba (2002) endossa isso ao relacionar o ensino do léxico ao dicionário:

O desenvolvimento da Linguística Textual, da Pragmática e dos estudos sobre aquisição do vocabulário tem demonstrado que os dicionários de língua não devem apresentar as palavras como unidades de sentido isoladas, mas, antes, em função da combinatória com outras palavras e estruturas. Assim, deve ser dada atenção especial às relações gramaticais e às propriedades colocacionais. (BORBA, 2002, p. 6) 
Escolher palavras adequadas em uma determinada situação de comunicação não depende apenas de conhecer os termos a serem usados e seus significados, mas também da sua capacidade de associação, que deve estar presente nessa articulação. Cada indivíduo desenvolve sua estratégia comunicativa, usando seus conhecimentos de léxico e também da situação em que se encontra. $\mathrm{O}$ mesmo ocorre quando, ao invés de produzir, ele interpreta. Nesse, deve-se unir o conhecimento que se possui do léxico à sua experiência em relação ao mundo, criando assim sua interpretação do que acaba de ouvir ou ler.

Bechara (2011, p. 9) diz que "o léxico é a janela da língua para o mundo e reflete a história cultural e social do povo que dela se serve como instrumento de comunicação e expressão". Logo, o léxico sofre constantes mutações porque reflete os hábitos culturais e sociais de uma comunidade. A língua é um componente dinâmico e aberto; o todo das possibilidades semânticas que podem ser atribuídas a uma mesma palavra é indeterminável e se altera rapidamente. Além de as variantes não serem satisfatoriamente abordadas nos dicionários, considera-se também outra problemática em relação ao ensino de língua materna: a escola ainda tende a priorizar o ensino da norma, deixando, para um segundo plano, o valor usual (real) da língua. Em relação a isso, Neves (2011) afirma que

Foi à escola, como espaço institucional privilegiado de parametrização social, que tradicionalmente se confiou o papel de guardiã da norma regrada e valorizada, daquele bom uso que tem o poder de qualificar o usuário para a obtenção de passaportes sociais, e, portanto, para o trânsito ascendente nos diversos estratos. Foi por aí que se perpetuou, na educação escolar aquele esquema medieval de associação de modelo de uso com autoridade e com urbanidade, ligando-se sempre o bom uso linguístico à fixidez de parâmetros, e corrupção linguística à alteração e mudança. (NEVES, 2011, p. 44).

É justamente isto que a escola deve conseguir prover nas suas atividades de língua escrita: uma situação real que condicione o uso linguístico normativo sem denegrir o léxico habitual do aluno. O condicionamento da produção do aluno (tanto escrita quanto falada) é muitas vezes deficiente pelo fato de as atividades propostas recorrerem a rituais já estabelecidos pelas normas antes mesmo de ele se questionar sobre o que é gramática.

$\mathrm{O}$ trabalho escolar com conceitos inflexíveis e atividades engessadas pela norma faz com que a compreensão do léxico se torne ainda mais difícil e até mais distante, ainda que os dicionários estejam cada vez mais propensos a indexar definições baseadas no uso ${ }^{5}$ e, com isso, a serem mais completos e adequados ao ensino de língua materna. Afinal, indispensável é mostrar que "as palavras não só nomeiam; elas também possuem franjas semânticas, pesos específicos que se patenteiam na propriedade de suas escolhas e vestimentas que melhor atendam a compromissos da etiqueta social em relação ao gênero textual que se vai construir". (BECHARA, 2011, p. 4).

Para isso, é preciso um trabalho com dicionários que dê subsídios importantes para o estudo do léxico, que (re)construa o conhecimento da língua, que possibilite a análise e reflexão sobre questões socioculturais e principalmente sociolinguísticas, não subestimando os contrapontos existentes na língua materna.

Há ocorrências de língua (expressões idiomáticas, gírias, regionalismos, neologismos e provérbios) que devem ser abordadas com mais atenção e cuidado. Essas abordagens devem ocorrer tanto da parte de quem elabora um dicionário escolar, que pode, por exemplo, repensar a inclusão dessas ocorrências junto a ilustrações (sobretudo para os de crianças em

\footnotetext{
${ }^{5}$ Um exemplo desse tipo de compêndio é o Dicionário de usos do português do Brasil de Francisco da Silva Borba, lançado em 2002 pela editora Ática.
} 
séries iniciais), quanto da parte dos professores, que devem intermediar a leitura de significado que o aluno faz, esclarecendo as atribuições de sentido que o dicionário não dá conta.

\section{0 ensino do léxico e o dicionário}

Levando-se em conta que a descrição das unidades lexicais não atinge igualmente todos os falantes de uma língua, deve-se analisar, na escola, qual a necessidade de consulta a dicionários dos alunos em cada nível de aprendizagem conforme as disciplinas a serem trabalhadas, para que o uso de seu material seja otimizado. O tratamento que se dá à estrutura do verbete, à quantidade de palavras, gravuras e atribuições de sentidos, enfim, a toda a organização geral do volume deve se justificar pelas particularidades e necessidades do falante.

Alunos em processo de alfabetização devem dispor de dicionários que ofereçam um vocabulário de fácil entendimento, com ilustrações, definições oracionais, com linguagem simples, interativa e inclusive coloquial, pois seu estágio de aquisição de vocábulos (em relação ao total das possibilidades) é primário e deve acompanhar o nível de dificuldade das atividades propostas na escola. E à medida que o aluno adquire o entendimento de uma maior quantidade de palavras, os exercícios de vocabulário vão se tornando gradativamente mais complexos. Por isso, os dicionários precisam ser adequados à busca de informações que o aluno está apto a compreender naquele momento.

Se um aluno das séries iniciais, por exemplo, dispuser somente de dicionários usados pelas séries finais (que contemplem definições analíticas e complexas), a linguagem usada para se referir ao termo buscado por ele pode não ser compatível com os termos com que ele se encontra familiarizado. Isso faz com que não se atinja o objetivo de utilizar seu próprio léxico na atribuição de sentido que ele fará da palavra até então desconhecida. Nas séries finais do ensino fundamental e durante o ensino médio, é essencial que os alunos tenham acesso a vários tipos de dicionários pelo fato de suas pesquisas irem mais fundo em determinadas áreas do conhecimento, abrangendo termos técnicos e científicos que dificilmente estarão presentes em dicionários padrões ou minidicionários escolares. Alguns vocábulos, inclusive, são encontrados apenas em dicionários específicos de determinadas áreas do conhecimento.

A proposta lexicográfica dos dicionários adotados pela escola deve suprir as necessidades básicas de consulta dos alunos. Afinal, sabe-se que o mais comum é que a partir do sexto ano do ensino fundamental o aluno manifeste sua autonomia buscando a significação de termos comuns à sua realidade social, sobretudo a permeada pela convivência com seus pares de mesma faixa etária, que é, muitas vezes, pouco compreendida pelo professor.

Uma das soluções possíveis, além de uma atualização constante do acervo, da otimização da abordagem ao dicionário e da seleção de exemplares destinados a determinadas séries, é a aquisição de dicionários voltados às áreas específicas de conhecimento; indispensáveis por favorecerem o acesso constante a novas palavras dentro da escola. Afinal, ensinar léxico é aproximar o aluno, o máximo possível, das possibilidades totais de que dispomos em nossa língua, desde a compreensão de significados e usos até as regras que classificam o normativo e o usual, e o que há de comum entre regra e uso nessa língua.

Durante a formação escolar do indivíduo, é necessário o conhecimento mínimo do vocabulário específico de cada área (tecnologia, ciências naturais, ciências sociais, etc.). Por isso, a proposta de uso de dicionários específicos não deve ser vista como uma realidade distante ou como se as definições dos dicionários escolares não fossem claras e suficientes, mas como um meio a fomentar uma abordagem particular e esmiuçada do conteúdo em 
questão, se valendo de mais tempo, espaço e planejamento para abordar criteriosamente um maior número de palavras.

Não são raras as vezes em que o aluno se depara com palavras desconhecidas, tanto nas atividades escolares como em outras experiências do cotidiano. Dentre tantos exemplos do dia a dia podemos citar um fato curioso ocorrido com um aluno do sétimo ano da rede pública que resolveu perguntar o significado da palavra ufologia. Fato é que, após ter sido induzido a buscar a palavra nos dicionários disponíveis na biblioteca da escola, ele descobriu que nenhum deles oferecia o significado dessa palavra.

Outro caso ocorreu com alunos de quarto e quinto anos. Na tentativa de abordarmos questões simples de etimologia a partir do trabalho com a base lexical -fobia, deparamo-nos com outro problema: os dicionários escolares apenas registravam os dois casos mais populares, a saber, a aracnofobia e a claustrofobia. As demais palavras buscadas nesses dicionários, como entomofobia e rupofobia, não foram encontradas. Uma solução interessante seria um dicionário de psicanálise que elencasse vários tipos de fobias. Afinal, a maioria dos alunos entende que -fobia indica o medo mórbido ou patológico, mas não sabe que há diversas palavras compostas por esse sufixo e que indicam diferentes medos humanos.

Pode-se alegar que mesmo sem dicionários específicos, o professor poderá propor pesquisas extraclasses. O problema é que muitas atividades realizadas na escola necessitam de resultados imediatos (mesmo que provisórios) para serem concluídas. Afinal, se o foco da aula é a etimologia das palavras, é ali que se deve descobrir que terafobia se refere ao medo de monstros, macairofobia ao medo de facas, distiquifobia ao de acidentes, ligirofobia ao de barulhos altos e assim por diante.

Vale ressaltar também que o mesmo problema ocorre durante os estudos de história antiga, que é entendida, basicamente, a partir da compreensão da função que cada um dos deuses mitológicos supostamente exercia na sociedade da época, pois os dicionários escolares não possuem a definição dos principais nomes estudados na escola. A maior parte dos nomes de deuses egípcios, gregos, entre outros, incluindo Ísis (deusa da fertilidade), Osíris (deus dos mortos), Hórus (deus dos céus e horizontes), Zeus (rei dos deuses), Perséfone (rainha dos mortos), Poseidon (deus do oceano), Atena (deusa da sabedoria), Ares (deus da guerra) não constam nos dicionários escolares.

Esse dilema é citado aqui pelo fato de usarmos palavras originárias do grego com origem mitológica, como é o caso da palavra cronológico, que surgiu a partir do Deus Kron (deus do tempo), o que não é aclarado na grande maioria dos dicionários escolares. O mesmo ocorre com a palavra gineceu, que era a parte da casa onde ficavam as mulheres na Grécia Antiga, e hoje é usada apenas para denominar a parte feminina da flor, sem qualquer menção a termos corriqueiros ao quais deu origem, a saber, ginecologia, ginecologista, etc.

Os provérbios, por sua vez, que são ditos populares utilizados em diferentes culturas, distanciam-se do sentido lógico atribuível a cada uma das unidades lexicais que os compõem. Em se tratando de alunos do ensino fundamental, por exemplo, essa interpretação de sentido muitas vezes não acontece e, ao recorrer ao dicionário, este não contribui, pelo fato de possuir somente uma significação literal que não comportaria a junção de determinadas palavras que ocorrem em provérbios. Observemos dois provérbios ${ }^{6}$ bastante utilizados no Brasil:

(1) Começou a chover durante a feira, hoje sim a vaca foi pro brejo.

(2) Ela botava a mão no fogo pelo marido.

Nos exemplos acima, podemos analisar em (1) que ainda que o aluno já saiba, ou mesmo que encontrou no dicionário as palavras "vaca" e "brejo", não chegará à definição de

\footnotetext{
${ }^{6}$ Não houve critério formal na seleção dos provérbios e dos exemplos apresentados nesse texto. São ocorrências de língua que veem nos inquietando já há algum tempo no dia a dia da sala de aula.
} 
que algo deu errado. O mesmo ocorre em (2) cujas definiç̧̃es do dicionário jamais chegarão à definição de "confiança" a que a locução se refere.

Em resumo à questão das especificidades, os casos acima demonstram a necessidade de introduzir os alunos na lida de dicionários como os de etimologia, etnologia, biologia, etc. Estes compêndios contribuirão à busca do sentido das palavras de modo dinâmico, trazendo consigo uma definição mais acertada e elucidando o aluno sobre o assunto. Nessa perspectiva, o dicionário estará a serviço do público a que se dirige, tendo enaltecido seu zelo descritivo e a sua representatividade.

\section{Repensando o dicionário em sala de aula}

Boa parte dos problemas abordados nas seções anteriores não é de fácil solução, pois, na maioria das vezes, as escolas não dispõem de recursos para aquisição de novos dicionários e, quando os recebem, não lhes é permitido escolher. Faz-se, então, necessário que o professor esteja ciente de que seu aluno precisará de mais de um dicionário para compreender algumas propriedades do léxico, que as atividades devem contextualizar essas palavras e que essa construção deve ser intermediada pelo professor e pelo grande grupo, pois, no ensino de língua materna, os fatores sociais são determinantes. Para que o uso de dicionários, de todos os tipos, possa contribuir de forma satisfatória aos professores e alunos no estudo da língua materna, a primeira providência a ser tomada, em qualquer nível de aprendizagem, é a de (re)conhecer o compêndio, dominá-lo e identificá-lo como um tipo de livro diferenciado. Explorar aspectos como guia de usuário, proposta lexicográfica e critérios de seleção lexical e entender a demanda para a qual o dicionário foi destinado é um fator decisivo na hora de consultá-lo.

Ainda que pareça evidente a necessidade de se ter fácil acesso aos dicionários durante as aulas, em muitas escolas isso não ocorre e os motivos são diversos: a quantidade limitada de dicionários, a obrigatoriedade de sua permanência em uma biblioteca (algumas vezes distante da sala de aula), dicionários desatualizados, entre outros.

Portanto, deve-se levar em conta a mobilidade desses compêndios na escola e qual a melhor maneira para resolver os problemas primordiais em relação ao seu uso. O professor deve se enquadrar na melhor das possibilidades a fim de proporcionar o uso do dicionário em sala de aula. É relevante que comecemos pelo momento mais importante: ensinar a consultar um verbete a partir de atividades focadas no entendimento do dicionário e dos vocábulos. $\mathrm{Na}$ prática, o processo de ensino e aprendizagem do uso de um dicionário se completa a partir do momento em que as informações, depois de devidamente compreendidas, são incorporadas ao vocabulário do aluno. Ainda que ele não utilize verbalmente a palavra, ele a compreenderá e a contextualizará quando se deparar com ela uma segunda vez. Cabe ao professor conscientizar os alunos de que a língua viva e real é sempre mais complexa, variada e mais dinâmica do que os termos descritos nos verbetes. É essa língua que o aluno precisa conhecer; ela deve ser o parâmetro para a análise de qualidade do dicionário.

É importante ressaltar que um dicionário só será efetivamente entendido como uma ferramenta se, além de saber que ele existe, para que serve e como funciona, o aluno fizer parte de situações concretas em que seu uso na escola ou em casa seja oportuno e útil. A utilização do dicionário deve ser agregada a quaisquer atividades de ensino que suscitem as particularidades da língua em uso. O aluno deve ser instigado a pensar sobre:

- Como se escreve uma palavra.

-Quais os sentidos possíveis.

-Quais as ocorrências possíveis. 
-Que sinônimos ou antônimos tem essa palavra.

•Quais articulações de uso lhe são comuns.

Assim, convém que o professor avalie o grau de letramento de seus alunos em relação aos dicionários antes de iniciar o trabalho, adaptando sempre as atividades conforme a necessidade. As atividades com dicionários não podem ser intituladas em grau de dificuldade, pela série em que o aluno se encontra, e sim baseadas no conhecimento que os alunos já possuem em língua materna, objetivando aprimorá-la.

O uso do dicionário deverá desenvolver no aluno a capacidade e o hábito de pesquisar a própria língua, de buscar sentidos, relações entre as palavras, de entender que há múltiplos significados: ora literais, ora figurados, ora metafóricos. Sempre de forma fascinante e envolvente. Para isso, é preciso que os dicionários deem subsídios importantes para o estudo da semântica do léxico, que (re)construam o conhecimento da língua, que possibilitem a análise e reflexão sobre questões socioculturais e principalmente sociolinguísticas, não subestimando os contrapontos existentes na língua materna.

Afinal, são as particularidades das línguas naturais que devem ser abordadas com mais atenção e cuidado, sobretudo da parte dos professores, que devem intermediar essa leitura de significado que o aluno faz, esclarecendo quanto às atribuições de sentido que o dicionário, por melhor que seja, não o faz.

\section{Considerações finais}

O que discutimos neste artigo pretendeu colaborar ao ensino do léxico por pelo menos dois vieses. Um primeiro epistemológico, em que refletimos sobre a realidade do ensino de semântica na escola básica vislumbrando o percurso linguístico-cognitivo do aluno. Outro, linguístico que se valeu de posicionamentos como os de Bechara (2011), Culioli (2002) e Neves (2011) que comungam ao admitir que os significados das palavras se estabelecem a partir da nossa experiência individual, coletiva e histórica; portanto, que são dinâmicos e flexíveis, não cabendo sua totalidade em nenhum dicionário, por mais que este seja comprometido com o léxico.

Assim, este estudo colocou como pano de fundo a necessidade de um fazer pedagógico que oriente o aluno em relação às vicissitudes da significação lexical desde os primeiros níveis de aprendizagem da escola básica. Buscamos incentivar as construções de relações de sentidos a partir da exploração das experiências prévias dos alunos (vivências da linguagem), fazendo associações dessas experiências com atividades de língua. Como um segundo ganho, chegamos a um repensar do dicionário em sala de aula: uma ferramenta de desenvolvimento interpretativo do aluno a partir da reflexão sobre o funcionamento da linguagem e do léxico tomado como um todo articulado e dinâmico. Afinal, desde que as ciências do significado ganharam espaço na educação, é disso que começamos a falar.

\section{Referências}

BECHARA, E. Dicionário escolar da academia brasileira de letras. 3. ed. São Paulo: Companhia Editora Nacional, 2011.

BIDERMAN, M. T. C. Teoria Lingüística: lingüística quantitativa e computacional. Rio de Janeiro: LTC, 1978. 
BORBA, F. S. da. Dicionário de Usos do Português do Brasil. São Paulo: Ática, 2002.

CULIOLI, A. Variations sur la linguistique. Paris: KlincKsieck, 2002.

CUMPRI, M. L. Produção e o ensino do texto: um desafio à legitimação da linguagem em sala de aula. Revista L@el em (Dis-)curso. Volume 3, 2011. Disponível em: <http://revistas.pucsp.br/index.php/revlael/article/view/2009/4367>. Acesso em: 16 jun. 2014.

KLEIMAN, A. Oficina de leitura: teoria \& prática. Campinas: Pontes, 1998.

NEVES, M. H. de M. Que gramática estudar na escola? 4. ed. São Paulo: Contexto, 2011.

SCARPA, E. M. Aquisição da Linguagem. In.: MUSSALIM, F.; BENTES, A. C. (Orgs.) Introdução à Linguística: domínios e fronteiras. São Paulo: Cortez, 2009, p. 203-232.

Recebido em: junho de 2015.

Aprovado em: setembro 2015. 